\title{
Linolenic Acid
}

National Cancer Institute

\section{Source}

National Cancer Institute. Linolenic Acid. NCI Thesaurus. Code C997.

An essential fatty acid belonging to the omega-3 fatty acids group. It is highly concentrated in certain plant oils and has been reported to inhibit the synthesis of prostaglandin resulting in reduced inflammation and prevention of certain chronic diseases. 